\title{
AVALIAÇÃO DO POTENCIAL DE DESCOLORAÇÃO E DE DETOXIFICAÇÃO DE CORANTES TÊXTEIS POR LACASE DE PLEUROTUS SAJOR-CAJU
}

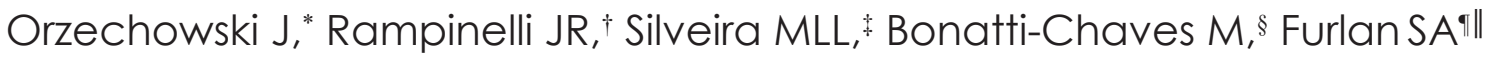

\section{Resumo}

As águas residuárias são normalmente um empecilho ambiental para 0 desenvolvimento da indústria têxtil em razão do gerenciamento inadequado e/ou tratamento ineficaz, que levam à contaminação da biota. Efluentes de indústrias têxteis têm como uma de suas principais características a alta carga de corantes, os quais durante o processo produtivo não se aderiram à fibra e, assim, encontramse presentes no efluente final. Estes, quando lançados no ambiente aquático, reduzem a disponibilidade de luz e a realização da fotossíntese e ocasionam outros problemas ambientais. Além disso, a maioria dos corantes têxteis são

\footnotetext{
*Graduada em Engenharia Química pela Universidade da Região de Joinville; julianaorzechowski@ gmail.com

† Doutora em Engenharia Química pela Universidade Federal de Santa Catarina; Mestre em Engenharia de Alimentos pela Universidade Federal de Santa Catarina; Professora na Universidade da Região de Joinville; jamile.r@univille.br

‡ Doutora em Bioquímica pela Universidade Federal do Paraná; Mestre em Engenharia de Alimentos pela Universidade Federal de Santa Catarina; Professora na Universidade da Região de Joinville; marcia.luciane@univille.br

§ Doutora e Mestre em Engenharia Química pela Universidade Federal de Santa Catarina; Professora na Universidade da Região de Joinville; Rua Paulo Malschitzki, 10, Zona Industrial Norte, 89219-710, Joinville, Santa Catarina, Brasil; mariane.bonatti@univille.br

" Doutora em Engenharia de Processos pela Escola Superior de Engenharia Química do Instituto Nacional Politécnico de Tolouse, França; Mestre em Engenharia Química pela Escola Superior de Engenharia Química do Instituto Nacional Politécnico de Tolouse, França; Professora na Universidade da Região de Joinville; sandra.furlan@univille.br
} 
tóxicos, mesmo em pequenas concentrações. Enzimas produzidas por Pleurotus sajor-caju são reportadas como eficientes na remoção de cor, degradação de corantes e detoxificação de efluentes têxteis. Assim, neste trabalho teve-se como objetivo avaliar a capacidade do caldo enzimático bruto de Pleurotus sajor-caju em remover a cor e, concomitantemente, diminuir a toxicidade de soluções que contêm os corantes têxteis Red 50 e Blue 56 (100 mg L-1). Para tal, produziu-se o caldo enzimático em biorreator (volume útil de $4 \mathrm{~L}$ ), que foi adicionado diretamente sobre a solução de corantes sem diluição, diluído em água (1:1) e diluído em solução ABTS (2,2'-azino-bis(3-etilbenzotiazolina-6-sulfônico)) (1:1). O microcrustáceo Daphnia magna foi utilizado nos testes ecotoxicológicos. Observou-se maior eficiência na remoção de cor pelo caldo enzimático bruto de P. sajor-caju diluído em solução ABTS (taxas de remoção 1,3 e 1,9×10-2 mg U-1 h-1, para os corantes Red 50 e Blue 56, respectivamente). A enzima lacase foi quantificada no caldo enzimático (115 U L-1) e manteve $100 \%$ de sua atividade durante todos os experimentos. Observouse redução estatisticamente significativa da toxicidade para o corante Blve 56. O corante Red 50 manteve-se tóxico mesmo após o tratamento enzimático, sugerindo a necessidade de maior tempo de reação para esse corante. O caldo enzimático bruto de P. sajor-caju mostrou-se eficaz e de uso promissor em estações de tratamento de efluentes têxteis.

Palavras-chave: Basidiomicetos. Caldo enzimático. Ecotoxicidade.

\section{Evaluation of the potential of decolorization and detoxification of textile dyes by laccase from Pleurotus sajor-caju}

\section{Abstract}

Wastewater is an environmental constraint for the development of the textile industry, since sometimes due to inappropriate management and/or ineffective treatment, it leads to contamination of biota. One of the main characteristics of textile wastes is the high amount of dye which, during the production process did not adhere to the fiber, thus appearing in the final waste. These wastes, when released into the aquatic environment reduce the availability of light, photosynthesis, as well as other environmental problems. Furthermore, these compounds are mostly toxic, even in small concentrations. Enzymes produced by Pleurotus sajor-caju are reported as efficient in color removal, dye degradation and detoxification of textile wastes. The objective of this study was to evaluate the ability of Pleurotus sajor-caju crude enzyme broth to remove color and reduce the toxicity of solutions containing Red 50 and Blue 56 dyes $\left(100 \mathrm{mg} \mathrm{L}^{-1}\right)$. For such, production of the enzyme broth was carried out in a bioreactor (working volume of $4 \mathrm{~L}$ ), which was used directly on the dye solution, diluted in water 1:1) and diluted in ABTS (2,2'-azino-bis (3-ethylbenzthiazoline-6sulfonic acid)) (1:1). Ecotoxicological tests were performed using the freshwater 
crustacean Daphnia magna. Higher efficiency in color removal by the crude enzymatic broth of $P$. sajor-caju diluted in ABTS solution was observed (removal rates equal to 1.3 and $1.9 \times 10^{-2} \mathrm{mg} \mathrm{U}^{-1} \mathrm{~h}^{-1}$, for dyes Red 50 and Blve 56, respectively). The laccase enzyme was quantified in the enzyme broth (115 U $\left.\mathrm{L}^{-1}\right)$ and maintained its activity $100 \%$ throughout all assays. A statistically significant reduction in toxicity was observed for Blue 56 dye. Red 50 dye remained toxic even after the enzymatic treatment, suggesting the need for a longer reaction time for this dye. The $P$. sajorcaju crude enzyme broth proved to be effective and promising for use in textile wastewater treatment plants.

Keywords: Basidiomycetes. Enzymatic broth. Ecotoxicity.

\section{INTRODUÇÃO}

Efluentes produzidos e liberados em rios por indústrias do setor têxtil representam na atualidade um grande problema ambiental. $\bigcirc$ volume desse tipo de efluente tem aumentado proporcionalmente nas últimas décadas em decorrência do crescimento populacional e do desenvolvimento da sociedade. Agregado a isso, o gerenciamento indevido e um tratamento ineficaz desse tipo de efluente podem comprometer seriamente o ambiente no entorno dessas indústrias. De acordo com o reportado em literatura, o setor têxtil é responsável pela geração de muitos compostos recalcitrantes, como os corantes, que não se aderem $100 \%$ à fibra natural ou sintética durante o processo de tingimento e, durante a etapa de lavagem, são liberados juntamente com o efluente para o ambiente. Assim, efluentes têxteis geralmente apresentam forte coloração, afetando severamente a vida aquática. Os corantes presentes nos rios absorvem a luz solar diminuindo sua disponibilidade para os sistemas de fotossíntese, ocasionando a privação de oxigênio e, consequentemente, a interrupção da cadeia alimentar aquática. Além disso, efluentes da indústria têxtil, comumente, apresentam elevada carga orgânica, apresentando altos valores de demanda química de oxigênio (DQO) e demanda biológica de oxigênio (DBO).1-3

Os corantes têxteis podem ser classificados de acordo com sua estrutura química (antraquinona, azo, entre outros) ou de acordo com o método pelo qual ele é fixado à fibra têxtil. Os corantes que apresentam em sua estrutura química o grupamento cromóforo azo (-N=N-) são os mais comuns e representam de 60 a $70 \%$ de todos os corantes sintéticos têxteis produzidos. De acordo com a Figura 1, unidos aos nitrogênios do grupo cromóforo encontram-se, de cada lado, átomos de carbono, normalmente, sistemas de anéis aromáticos. ${ }^{4,5}$ 


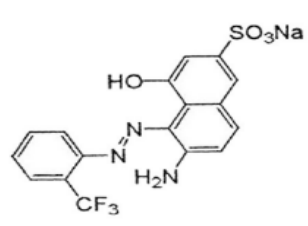

Cl Acid Red 337

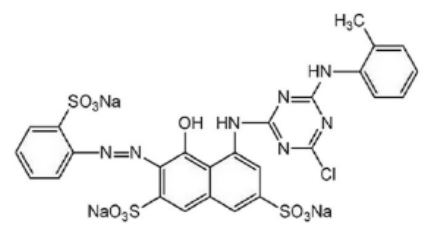

CI Reactive Red 198

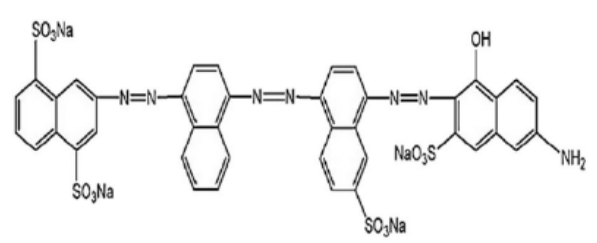

CI Direct Blue 71

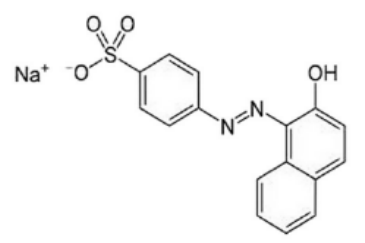

CI Acid Orange 2

Figura 1 - Estrutura química de alguns azocorantes (corantes azóicos) Fonte: Singh, Singh e Singh. ${ }^{5}$

Os corantes contendo em sua estrutura química a função antraquinona constituem outra classe de corantes importantes para a indústria têxtil. Eles apresentam o grupo cromóforo carbonila $(C=O)$, sendo na grande maioria observada a presença de dois ou mais desses grupos ligados a um sistema de anéis aromáticos, ${ }^{4}$ como exemplificado na Figura 2, por meio da estrutura química do corante Remazol Brilliant Blue R.

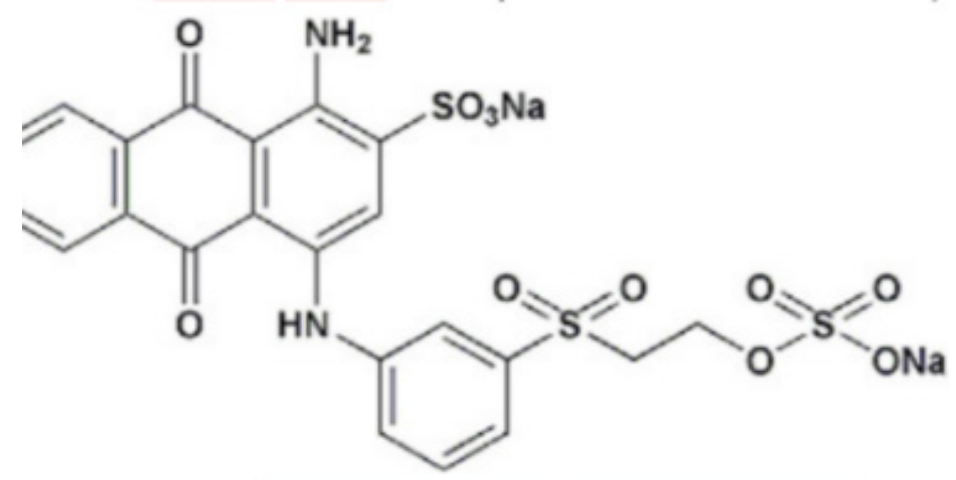

Figura 2 - Estrutura química do corante Remazol Brilliant Blue R, pertencente à classe das antraquinonas

Fonte: Zhang, Zhang, He, Qin, Zhang e Yang. ${ }^{9}$

O corante Remazol Brilliant Blue R é considerado um organopolvente tóxico e recalcitrante. É um composto derivado do antraceno, que apresenta elevada toxicidade, em razão do comportamento químico similar ao dos compostos pertencentes à família dos hidrocarbonetos policíclicos aromáticos (HPA). ${ }^{6}$ Muitos corantes têxteis são classificados como tóxicos.

Fungos do gênero Pleurotus são reconhecidamente bons produtores de enzimas, ${ }^{7-10}$ capazes de degradar compostos orgânicos complexos contendo anéis aromáticos em sua estrutura," como os corantes. A espécie Pleurotus ostreatus mostrou-se eficiente na degradação do corante Remazol Brilliant Blue R, por 
exemplo, sendo o meio de cultivo que contém o corante (50 ppm) totalmente descolorido em três dias. ${ }^{12}$ Entre as enzimas quantificadas pelos autores, as lacases parecem ter função primordial e foram as responsáveis pela degradação do corante Remazol Brilliant Blue R. Concomitantemente, os autores observaram ao final do experimento redução de $95 \%$ na toxicidade do meio. Outros autores também sugerem a degradação de corantes têxteis em razão da atuação da enzima lacase. $5,7,8,13$

Lacases pertencem à família das multi-cobre azuis oxidases (OMC), com capacidade de oxidar, polimerizar ou transformar compostos fenólicos, não fenólicos e antropogênicos em derivados menos tóxicos. Dessa forma, são consideradas de grande potencial para utilização em diversos processos de remediação em substituição aos processos químicos, promovendo ações ecologicamente sustentáveis. ${ }^{14,15}$

Outros autores têm se dedicado a investigar a eficiência da remoção/ degradação de corantes têxteis por lacases fúngicas. Pohl' ${ }^{16}$ observou percentual de descoloração igual a 53\% para o azocorante Azul Drimaren CL-R (50 mg L-1) em 72 horas, utilizando o caldo enzimático bruto de Pleurotus sajor-caju na concentração de 10\% (295 U L-1). Kroetz ${ }^{17}$ avaliou a capacidade de descoloração do caldo enzimático bruto de Pleurotus sajor-caju (48,5 U L-1) para os azocorantes Azul de Tripan e Congo Red (50 mg L-1 ). Utilizando-se 10\% do caldo enzimático na composição do meio reativo, foi possível observar em 72 horas a descoloração de 78 e $71 \%$ para os corantes Azul de Tripan e Congo Red, respectivamente.

Concomitantemente à degradação, acontece, normalmente, a diminuição da toxicidade do efluente. ${ }^{12}$ Uma forma de se quantificar a toxicidade de um composto ou solução é a realização de testes ecotoxicológicos, como, por exemplo, teste com o microcrustáceo Daphnia magna. Esses organismos filtram a água do meio onde vivem para se alimentarem da matéria orgânica em suspensão retida no processo de filtração, sendo considerados consumidores primários. Assim, por meio da sua taxa de mortalidade ou inibição da mobilidade, obtêm-se informações sobre a toxicidade do composto, solução ou efluente. ${ }^{18}$

Além disso, segundo a Resolução n. 357, de 17 de março de 2005, do Conselho Nacional do Meio Ambiente (Conama), o efluente de qualquer fonte polvidora só poderá ser lançado direta ou indiretamente nos corpos hídricos se não ocasionar ou possuir potencial para acarretar efeitos tóxicos aos organismos aquáticos no corpo receptor. ${ }^{19}$

Dessa forma, objetivou-se com o presente estudo avaliar a capacidade de descoloração de corantes têxteis pelo caldo enzimático bruto de Pleurotus sajorcaju, e por meio de teste agudo, utilizando-se o microcrustáceo Daphnia magna, analisar a toxicidade da solução contendo o corante, antes e após tratamento enzimático, visando à produção de uma formulação enzimática para aplicação em efluentes da indústria têxtil. 


\section{MATERIAIS E MÉTODOS}

\subsection{MICRO-ORGANISMO E MANUTENÇÃO}

Aespécie Pleurotussajor-caju, obtida da Coleção de Cultura de Basidiomicetos do Instituto de Botânica (São Paulo) sob o código CCB 019, foi mantida em meio sólido TDA (Trigo, Dextrose e Ágar), composto por $20 \mathrm{~g}$ de dextrose e $15 \mathrm{~g}$ de ágar, dissolvidos em $1,0 \mathrm{~L}$ de extrato de trigo..$^{20} \mathrm{~A}$ cultura foi conservada sob refrigeração a $4^{\circ} \mathrm{C}$, e os repiques foram realizados a cada três meses.

\subsection{OBTENÇÃO DO CALDO ENZIMÁTICO BRUTO DE PLEUROTUS SAJOR-CAJU}

O meio de cultivo utilizado para a produção do caldo enzimático foi o OXI 45 composto por $30 \mathrm{~g} \mathrm{~L}^{-1}$ de glicose, 5,4 mM de tartarato de amônio, 150 M de sulfato de cobre anidro e $45 \mathrm{~g} \mathrm{~L}^{-1}$ de pó de cascas de banana, dissolvidos em água de imersão de folhas secas de bananeira. ${ }^{21}$ Essa água foi obtida por meio da imersão de $150 \mathrm{~g}$ de folhas secas de bananeira, previamente secas a $60^{\circ} \mathrm{C}$, em $3 \mathrm{~L}$ de água destilada. Após 12 horas em imersão, separaram as folhas do líquido gerado, e este foi filtrado em papel filtro quantitativo faixa preta (C41, velocidade rápida, 125mm, UNIFIL).

Os inóculos foram preparados em frascos Duran de $2 \mathrm{~L}$ contendo $400 \mathrm{~mL}$ (i.e., $10 \%$ do volume útil do biorreator) de meio de cultivo, sem adição de pó de cascas de banana e sulfato de cobre. Os frascos foram inoculados com micélio de sete dias, contido em uma placa de Petri. Em seguida foram incubados a $30^{\circ} \mathrm{C} \mathrm{em}$ agitador (B. BRAUN, CERTOMAT U), com agitação recíproca de $110 \mathrm{~min}^{-1}$ por sete dias. ${ }^{22}$

O cultivo foi realizado em biorreator de mistura completa (B. BRAUN, BIOSTAT B), com volume útil de $4 \mathrm{~L}$. A temperatura foi controlada em $30^{\circ} \mathrm{C}$, a velocidade de agitação em $350 \mathrm{~min}^{-1}$, a aeração em 0,37 vvm e o pH inicial ajustado em 6,0, conforme definido em experimentos previamente realizados por Furlan. ${ }^{21} \mathrm{O}$ tempo de cultivo foi de aproximadamente seis dias, a fim de se obter máxima atividade de lacase. ${ }^{21}$ Ao final do cultivo, o caldo enzimático bruto foi centrifugado a 5.000 min $^{-1}$ por cinco minutos para separação da biomassa e partículas sólidas maiores, e congelado $\left(-18^{\circ} \mathrm{C}\right)$ até início dos experimentos.

\subsection{ENSAIOS DE DESCOLORAÇÃO E DETOXIFICAÇÃO}

Foram avaliados os valores de $\mathrm{CE}_{50}$ (concentração efetiva mediana), contidos nas Fichas de Informação de Segurança de Produto Químico (FISPQ) dos 11 corantes, gentilmente cedidos por uma empresa têxtil localizada em Guaramirim (Tabela 1). Não foi autorizada pela empresa fabricante/fornecedora dos corantes a divulgação de seu nome. Selecionaram-se para estudo dois corantes: Red 50 e Blue 56, ambos com valor de $\mathrm{CE}_{50} 100 \mathrm{mg} \mathrm{L}^{-1}$ e de coloração bastante diferentes. 
Tabela 1 - Nome, valor de $\mathrm{CE}_{50}$ e cor dos corantes utilizados pela empresa**

\begin{tabular}{|l|r|c|}
\hline Corantes & $\mathbf{C E}_{50}\left(\mathbf{m g ~ L}^{-1}\right)$ & Cor \\
\hline Disperse Yellow 211 & $>200$ & \\
\hline Disperse Blue 183 & $>100$ & $\mathbf{I}$ \\
\hline Blue 56 & $>100$ & \\
\hline Red 50 & $>100$ & \\
\hline Disperse Red 153 & $>200$ & \\
\hline Disperse Yellow 82 & $>100$ & \\
\hline Disperse Blue EX-SF & $>100$ & \\
\hline Disperse Red 352 & $>100$ & \\
\hline Disperse Blue 60 & $>100$ & \\
\hline Disperse Red 277 & $>100$ & \\
\hline Disperse Red 60 & $>200$ & \\
\hline
\end{tabular}

Os experimentos foram realizados em tubos de ensaio, sendo o volume total de reação igual a 4,4 mL. Para tanto, em todos os experimentos utilizaram-se $2 \mathrm{~mL}$ de solução do corante ( $100 \mathrm{mg} \mathrm{L}^{-1}$, conforme valor de $\mathrm{CE}_{50}$ constante na FISPQ), 0,4 mL de solução tampão fosfato-citrato 0,05 M (pH 5) e, de acordo com o correspondente ensaio, $2 \mathrm{~mL}$ do caldo enzimático bruto (115 U L-1) (ensaio 1), ou $2 \mathrm{~mL}$ do caldo enzimático bruto diluído em água (1:1) (ensaio 2), ou $2 \mathrm{~mL}$ do caldo enzimático bruto diluído em solução ABTS (2,2'-azino-bis(3-etilbenzotiazolina-6-sulfônico) (1:1) (ensaio 3), e $2 \mathrm{~mL}$ do caldo enzimático bruto inativado por aquecimento a $100{ }^{\circ} \mathrm{C}$ por 15 minutos (atividade em lacase $0 \mathrm{U} \mathrm{L}^{-1}$, branco). As misturas foram incubadas em bancada em temperatura ambiente (média de $20^{\circ} \mathrm{C}$ ), sem agitação, sob influência de luz natural. Amostras foram retiradas nos tempos 0, 3, 6, 9, 12, 21 e 24 horas para determinação do percentual de descoloração, da atividade em lacase e do pH. Todos os experimentos foram realizados em triplicata.

Avaliou-se a toxicidade aguda para as soluções contendo os corantes puros Red 50 e Blve 56 (100 mg L-1) e para as soluções após o tratamento enzimático, para cada corante. Para tal, utilizou-se o tempo e o ensaio que proporcionaram maior percentual de descoloração. Os experimentos foram realizados em quadruplicata.

\subsection{MÉTODOS ANALÍTICOS}

\subsubsection{Determinação do percentual de descoloração}

Inicialmente determinou-se o comprimento de onda de maior absorção para cada corante usando espectrofotômetro UV-Visível (modelo 160A, SHIMADZU). Utilizou-se a faixa de leitura/varredura com comprimentos de onda de 400 a 800 nm. Em seguida, uma curva de calibração foi confeccionada para cada corante.

** $\mathrm{CE}_{50}$ : concentração efetiva mediana. 
Utilizando-se as curvas de calibração de cada corante, calculou-se a concentração do corante nas amostras, bem como os percentuais de descoloração. ${ }^{17}$

\subsubsection{Determinação da atividade em lacase}

Foi medida por meio da variação da absorbância em 420 nm, em espectrofotômetro UV-Visível (modelo 160A, SHIMADZU), produzida pela oxidação do composto ABTS (2,2'-azino-bis(3-etilbenzotiazolina-6-sulfônico), 1,8 mM, pH 4,2$5,8)$ (SIGMA), utilizado como substrato um volume de $0,8 \mathrm{~mL}$, ao qual se acrescentou $0,1 \mathrm{~mL}$ de solução tampão fosfato-citrato, com perborato de sódio, 0,05 M (pH 5) e $0,1 \mathrm{~mL}$ da solução teste..$^{23}$ Uma unidade de atividade enzimática foi definida como a quantidade de enzima necessária para oxidar $1 \mu \mathrm{mol}$ do substrato ABTS por minuto, utilizando o coeficiente de extinção molar de $36000 \mathrm{M}^{-1} \mathrm{~cm}^{-1}$. A Equação 1 foi utilizada para quantificação da atividade da lacase.

$$
\frac{\mathrm{U}}{\mathrm{L}}=\frac{\Delta_{a b s} \cdot \mathrm{V}}{\varepsilon \cdot d \cdot v \cdot t}
$$

em que $\Delta$ abs: diferença entre absorbância final e absorbância inicial; $\vee$ : volume total da reação $(\mathrm{mL})$; $\varepsilon$ : coeficiente de extinção molar $\left(\mathrm{M}^{-1} \mathrm{~cm}^{-1}\right)$; v: volume de amostra $(\mathrm{mL})$; d: comprimento do passo $(\mathrm{cm})$; t: tempo de reação (min).

\subsubsection{Determinação do pH}

Realizou-se a leitura do pH em pHmetro digital (METTLER TOLEDO) diretamente nas soluções contidas nos tubos de ensaio, em cada tempo de amostragem.

\subsection{TESTE DE TOXICIDADE AGUDA}

\subsubsection{Microcrustáceo e manutenção}

Testes de toxicidade aguda com as substâncias de referência foram realizados para garantir a credibilidade dos resultados e a qualidade dos organismos-teste. Utilizou-se a espécie Daphnia magna (Crustacea, Cladocera) cultivada no laboratório de Ecotoxicologia e Meio Ambiente da Universidade da Região de Joinville (Univille). Foram selecionados para os ensaios microcustáceos neonatos (2 a 26 horas) produzidos em lotes de cultivos com $\mathrm{CE}_{50^{\prime}}$ em 24 horas, entre $0,6 \mathrm{e}$ $1,7 \mathrm{mg} \mathrm{L}^{-1}$ de dicromato de potássio. ${ }^{24} \mathrm{~A}$ fim de se garantirem as características básicas do meio para manutenção, cultivo e realização dos testes de toxicidade, 
utilizando-se organismo proveniente de água doce, esse foi composto por cloreto de cálcio, sulfato de magnésio, cloreto de potássio e bicarbonato de sódio, sendo o pH mantido entre 7,0 e 8,0. ${ }^{18}$

Duas vezes por semana realizou-se a troca de meio de cultivo, sendo os microcustáceos mantidos em lotes de 25 adultos por litro, em cristalizadores, com luminosidade difusa pelo fotoperíodo de 16 horas de luz $\left(90 \mu \mathrm{E} \mathrm{s}^{-1} \mathrm{~m}^{-2}\right)$ e oito horas de escuro, e temperatura controlada entre 18 e $22^{\circ} \mathrm{C}$. Para a alimentação dos microcrustáceos utilizou-se suspensão de algas da espécie Scenedesmus subspicatus na quantidade aproximada de $10^{6}$ células $\mathrm{mL}^{-1}$ por organismo adulto, realizada diariamente ou com intervalos de no máximo dois dias consecutivos, na ocorrência de feriados e finais de semana. As algas foram mantidas em água reconstituída (meio Oligo), com luminosidade difusa, iluminação contínua $\left(90 \mu \mathrm{E} \mathrm{s}^{-1} \mathrm{~m}^{-2}\right)$, velocidade de agitação de $135 \mathrm{rpm}$ e temperatura de $25^{\circ} \mathrm{C} .{ }^{18}$

\subsubsection{Teste com Daphnia magna}

Utilizaram-se cinco neonatos de Daphnia magna por tubo de ensaio (ensaios em quadruplicata), sendo para cada ensaio realizado um teste controle, composto pelo meio natural para cultivo dos organismos. As diluições foram realizadas de forma decrescente, em termos de percentual da solução teste ( $100 \%$ a 0,5\%). Após o período de incubação, realizou-se a contagem de organismos imóveis/mortos em cada diluição com o auxílio de uma caixa de luz. Por fim, para a determinação da $\mathrm{CE}_{50}$ foi utilizado o programa estatístico Trimmed Spearman-Karber Method com a capacidade de analisar a toxicidade aguda de amostras a partir dos dados de mortalidade/imobilidade dos indivíduos teste.

\subsection{ANÁLISE ESTATÍSTICA}

O Teste $Q$ de Dixon, com nível de confiança de $95 \%$, foi utilizado a fim de avaliar a rejeição de valores desviantes para cálculo das médias. ${ }^{25}$ O Teste Tukey foi utilizado para se avaliar a existência de diferenças estatisticamente significativas entre as médias dos resultados, com nível de confiança de $95 \%$, e o programa Origin $7.5 \mathrm{PRO}^{\circledR}$ para confecção dos gráficos.

\section{RESULTADOS E DISCUSSÃO}

Observa-se, de acordo com a Figura 3 (a) e (b), o comprimento de onda de máxima absorção para o corante Red 50 igual a $490 \mathrm{~nm}$ e para o corante Blue 56 igual a $630 \mathrm{~nm}$. 

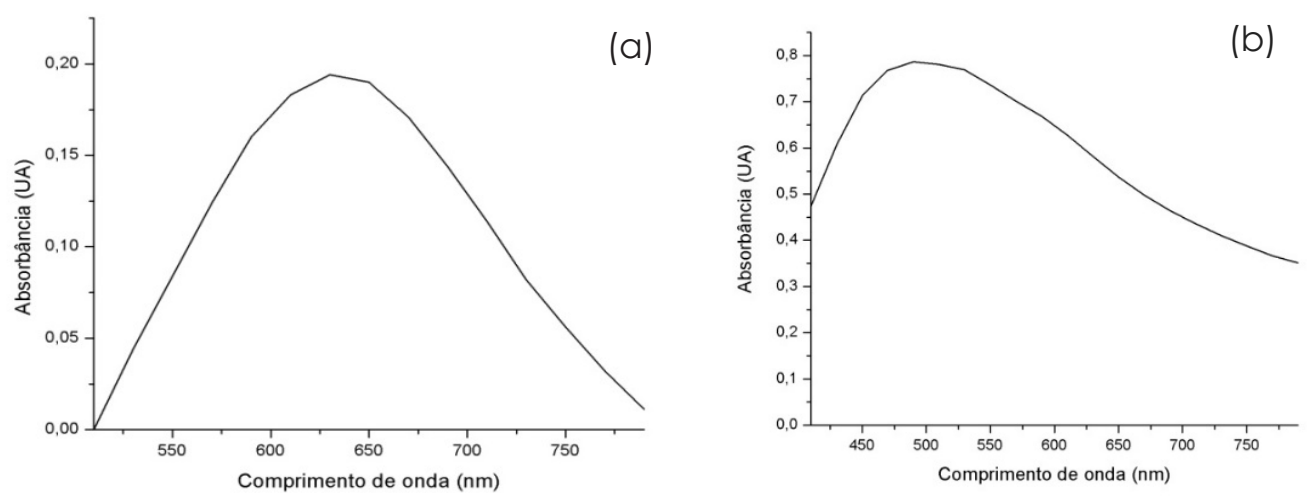

Figura 3 - Comprimento de onda de máxima absorção para os corantes (a) Red 50 e (b) Blue 56

Ambos os corantes (Red 50 e Blue 56) apresentam cores únicas, desenvolvidas e comercializadas para uso exclusivo do setor têxtil. Segundo Brown, ${ }^{26}$ um composto absorverá radiação visível quando aquela radiação possuir a energia necessária para mover um elétron de seu estado de energia mais baixo (fundamental) para um estado excitado. Assim, as energias específicas de radiação que uma substância absorve determinarão as cores que ela exibe. Um objeto tem uma cor específica por uma das duas razões: (1) ele reflete ou transmite luz/radiação daquela cor; (2) ele absorve luz/radiação da cor complementar.

No caso específico dos corantes utilizados neste trabalho, observa-se para o corante Red 50 maior absorção de radiação em 490 nm, ou seja, a cor que se enxerga é a cor complementar (vermelho) (Figura 4). O mesmo raciocínio pode ser utilizado para explicar a cor observada para o corante Blue 56, em que se observa maior absorção no comprimento de onda igual a $630 \mathrm{~nm}$, assim é absorvida a cor laranja e o restante é transmitido, formando sua cor complementar, dessa forma enxerga-se a cor azul.

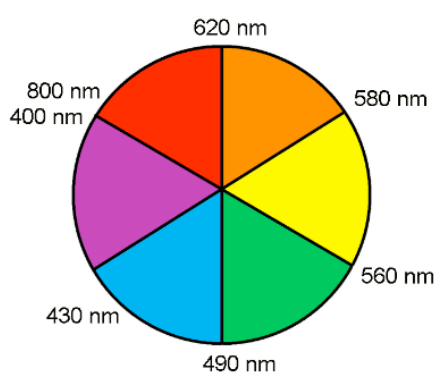

Complementar

Figura 4 - Disco de cores com os seus respectivos comprimentos de onda e representação da cor complementar

Fonte: adaptado de Wikimedia Common Contributor. ${ }^{27}$

A partir da determinação do comprimento de onda de máxima absorção de cada corante, curvas de calibração foram confeccionadas, sendo as equações da reta para os corantes Red 50 e Blue 56 iguais a $y=0,0108 x+0,0909$ e $y=0,0057 x+0,0582$, 
respectivamente. Os valores de $R^{2}$ para cada uma das equações foram 0,9824 para o corante Red 50, e 0,9876 para o corante Blue 56.

Durante o processo de tingimento em indústrias têxteis, três etapas são consideradas importantes: a montagem, a fixação e o tratamento final. A fixação do corante à fibra ocorre por meio basicamente de quatro tipos de interações: ligações iônicas, de hidrogênio, de Van der Waals e covalentes, ocorrendo usualmente durante as fases de montagem e fixação. Na etapa final, ou seja, na etapa de lavagem, em banhos correntes para a retirada do excesso do corante original, ou do corante hidrolisado não fixado à fibra, é gerado um dos maiores problemas ambientais observados para os efluentes têxteis: a sua forte coloração. ${ }^{3}$

Efluentes de indústrias têxteis apresentam como características principais elevada carga orgânica e forte coloração. A coloração, além de interferir esteticamente nos corpos hídricos, provoca diminuição da absorção da luz prejudicando a vida existente nesses ambientes. ${ }^{2}$

Um método alternativo à oxidação química e bastante promissor, sugerido neste trabalho para a remoção/degradação de corantes têxteis presentes em efluentes, e no ambiente, tem sido a oxidação biológica desses compostos. Fungos da podridão branca, em razão do seu complexo enzimático único, composto por enzimas como manganês peroxidases, lignina peroxidases, lacases, dentre outras, 7,10 vêm sendo cada vez mais estudados nos mais diversos processos de biorremediação como na biosorção de metais, ${ }^{28}$ no tratamento de áreas contaminadas por hidrocarbonetos aromáticos policíclicos (HAPs), ${ }^{29}$ na degradação de compostos interferentes endócrinos ${ }^{30}$ e na descoloração/degradação de corantes em efluentes têxteis. ${ }^{16,17,31}$

Os percentuais de descoloração obtidos neste trabalho para as soluções contendo os corantes Red 50 e Blue 56, ambos na concentração de $100 \mathrm{mg} \mathrm{L}^{-1}$, em experimentos utilizando o caldo enzimático bruto de Pleurotus sajor-caju (ensaio 1), o caldo enzimático diluído em água (1:1) (ensaio 2) e o caldo enzimático diluído em solução ABTS (1:1) (ensaio 3), nos tempos 0, 3, 6, 9, 12, 21 e 24 horas, são apresentados nas Figuras 5 e 6 , respectivamente.

Observa-se, de acordo com a Figura 5, maior percentual de remoção do corante Red 50 (15\%) no experimento que utilizou o caldo enzimático diluído em ABTS, em 21 horas de incubação. Esse valor foi estatisticamente superior aos obtidos nos experimentos com o caldo diluído em água $(11,7 \%)$ e sem diluição $(5,2 \%)$. Os percentuais de remoção do corante Red 50 são estatisticamente iguais para os tempos 21 e 24 horas, independentemente do caldo enzimático utilizado (sem diluição, diluído em água ou diluído em ABTS). 


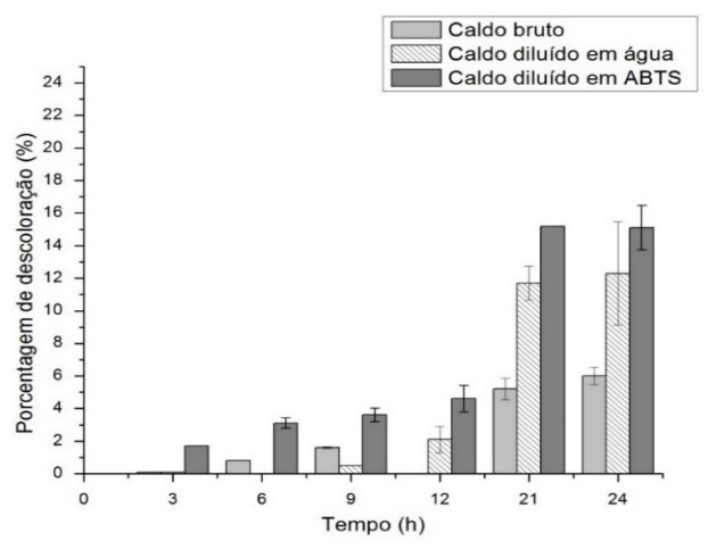

Figura 5 - Percentuais de descoloração \pm erro padrão, em função do tempo, para o corante Red 50

De acordo com a Figura 6, observam-se novamente maiores percentuais de remoção, agora para o corante Blue 56, nos experimentos que utilizaram o caldo enzimático diluído em ABTS, independentemente do tempo de incubação, sendo os maiores percentuais obtidos em 24 horas. Observa-se remoção de 22\%, em 24 horas, utilizando-se o caldo enzimático diluído em ABTS. Comparando-se os percentuais de remoção dos dois corantes, Red 50 e Blue 56, observa-se maior percentual de remoção, para o mesmo tempo de incubação, e independentemente do ensaio (1, 2 ou 3), para o corante Blue 56. Em um estudo realizado por meio de análise visual, em experimentos em placas de Petri, outros autores ${ }^{32}$ observaram maior facilidade de descoloração de corantes azuis do que de vermelhos por fungos basidiomicetos. Em seus experimentos, esses últimos praticamente não foram degradados. Os autores sugerem para o corante estudado, Vermelho Indanthren FBB, denominação Indanthren, uma estrutura química de mais difícil degradação, provavelmente relacionada ao tipo de grupamento cromóforo presente na molécula.

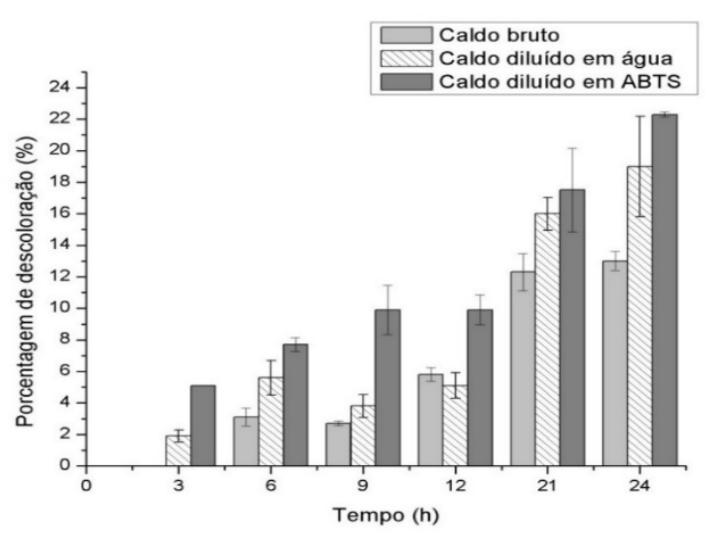

Figura 6 - Percentuais de descoloração \pm erro padrão, em função do tempo, para o corante Blue 56

Muitos autores afirmam que o sucesso em processos de descoloração por fungos se deve à presença da enzima lacase no meio reativo, estando sua 
capacidade de descoloração relacionada à similaridade das estruturas químicas do corante e do substrato natural da enzima, a lignina, permitindo, assim, a destruição dos grupamentos cromóforos do corante. . $^{8,15,31}$

O composto ABTS é considerado um substrato relevante para a atividade da enzima, podendo ser utilizado em meios de cultivo como mediador/indutor da atividade de lacase. A presença de substâncias oxidantes de baixa massa molar, denominados mediadores, como o ABTS, no ciclo biocatalítico da lacase aumentam sua atividade. A degradação/oxidação do polvente, ou do corante, nesse caso, envolve duas etapas oxidativas. Primeiramente, a lacase oxida 0 mediador, e em uma segunda etapa, o mediador oxida, ou seja, retira elétrons, do composto polvente." Estudos têm demonstrado o importante papel do ABTS na sua forma oxidada e, portanto, altamente reativa, como mediador nos processos de oxidação realizado pela lacase. ${ }^{33,34}$

Ainda, outros autores ${ }^{35}$ observaram aumento no percentual de descoloração do corante antraquinonico Remazol Brilliant Blue SN4R (100 mg L-1), em 10 horas de incubação, quando utilizaram caldo enzimático bruto de Pleurotus ostreatus (30 U $\mathrm{mL}^{-1}$, ou seja, $30.000 \mathrm{UL}^{-1}$ ) adicionado de ABTS ( $1 \mathrm{mM}$ ). O percentual de descoloração foi aumentado em aproximadamente $66 \%$ em relação ao experimento sem adição de ABTS. Em outro estudo ${ }^{31}$ observou-se percentual de descoloração para os corantes Drimaren Rubinol X-3LR e Drimaren Blue C-R (120 mg L-1) iguais a 90 e 82\%, respectivamente, em 24 horas, utilizando o caldo enzimático de Pleurotus ostreatus (255 $\mathrm{U} \mathrm{mL}^{-1}$, ou seja, $255.000 \mathrm{U} \mathrm{L}^{-1}$ ) obtido de cultivo em meio sólido. Segundo os autores, a adição de ABTS $(0,017 \mathrm{mM})$ ao meio reativo foi essencial para o processo de descoloração. ${ }^{31}$

Os percentuais de descoloração obtidos neste trabalho (15 e 22\%, em 21 e 24 horas de incubação, para os corantes Red 50 e Blue 56, respectivamente, utilizando o caldo enzimático diluído em ABTS) são muitas vezes inferiores aos reportados em literatura. Pohl' ${ }^{16}$ observou percentual de descoloração igual a 53\% para o azocorante Azul Drimaren CL-R (50 $\left.\mathrm{mg} \mathrm{L}^{-1}\right)$ em 72 horas, utilizando o caldo enzimático bruto de Pleurotus sajor-caju na concentração de 10\% (295 U L-1). Para o corante Vermelho Drimaren CL-5B, a autora não observou degradação. Kroetz ${ }^{17}$ avaliou a capacidade de descoloração pelo caldo enzimático bruto de Pleurotus sajor-caju dos azocorantes Azul de Tripan e Congo Red (50 mg L-1). Utilizando 10\% do caldo enzimático $\left(48,5 \mathrm{U} \mathrm{L}^{-1}\right)$ na composição do meio reativo, em 72 horas, a autora observou descoloração de 78 e $71 \%$ para os corantes Azul de Tripan e Congo Red, respectivamente. Contudo, quando, em vez da análise do percentual de descoloração individualmente se convertem esses valores em taxa ou eficiência de descoloração, levando-se em conta não somente o percentual de descoloração, mas também a atividade enzimática e o tempo de reação, observam-se valores superiores e/ou similares para os resultados obtidos neste trabalho (Tabela 2). 
Tabela 2 - Taxas de descoloração específica para lacases de Pleurotus ${ }^{t \dagger}$

\begin{tabular}{|c|c|c|c|}
\hline Fungo/Corante & $\begin{array}{r}\text { Taxa de } \\
\text { remoção } \\
\left(\% \mathrm{LU}^{-1} \mathrm{~h}^{-1}\right)\end{array}$ & $\begin{array}{r}\text { Taxa de } \\
\text { remoção } \\
\left(\mathrm{mg} \mathrm{U}^{-1} \mathrm{~h}^{-1}\right)\end{array}$ & Referência \\
\hline P. ostreatus/Remazol Brilliant Blue & $2,2 \times 10^{-4}$ & $2,2 \times 10^{-4}$ & $\begin{array}{l}\text { Hou, Zhou, } \\
\text { Wang, Du e } \\
\text { Yan }^{35}\end{array}$ \\
\hline $\begin{array}{l}\text { P. ostreatus/Drimaren Rubinol } \\
\text { X-3LR }\end{array}$ & $1,4 \times 10^{-5}$ & $1,8 \times 10^{-5}$ & $\begin{array}{l}\text { Teixeira, Pereira e } \\
\text { Ferreira-Leitão }{ }^{31}\end{array}$ \\
\hline P. ostreatus/Drimaren Blue C-R & $1,3 \times 10^{-5}$ & $1,6 \times 10^{-5}$ & $\begin{array}{l}\text { Teixeira, Pereira e } \\
\text { Ferreira-Leitão }{ }^{31}\end{array}$ \\
\hline P. sajor-caju/Azul Drimaren CL-R & $2,5 \times 10^{-3}$ & $1,2 \times 10^{-3}$ & Pohl' \\
\hline P. sajor-caju/Azul de Tripan & $2,2 \times 10^{-2}$ & $1,1 \times 10^{-2}$ & Kroetz $^{17}$ \\
\hline P. sajor-caju/Congo Red & $2,0 \times 10^{-2}$ & $1,0 \times 10^{-2}$ & Kroetz $^{17}$ \\
\hline P. sajor-caju/Red 50 & $1,3 \times 10^{-2 a}$ & $1,3 \times 10^{-21 a}$ & Este trabalho $2 \mathrm{c}$ \\
\hline P. sajor-caju/Blve 56 & $1,9 \times 10^{-2 b}$ & $1,9 \times 10^{-23 b}$ & Este trabalhoc \\
\hline
\end{tabular}

Além disso, são poucos os trabalhos citados em literatura que utilizam para os processos de descoloração o caldo enzimático bruto. A maioria estuda o percentual de descoloração ao longo do próprio cultivo, sólido ou líquido, do fungo, ou, ainda, utilizam a enzima extraída do caldo, purificada e imobilizada, nos experimentos. Este último acarreta custos elevados ao processo em razão das etapas de extração, purificação e imobilização da enzima. Neste trabalho utilizouse o caldo enzimático bruto de Pleurotus sajor-caju. Erkurt, 11 em experimentos relacionados à remoção do polvente bisfenol-A por lacases, observou maior percentual de remoção (100\% em 90 minutos), bem como maior estabilidade da enzima (atividade residual de 60\% em 90 minutos) nos experimentos em que utilizou o caldo enzimático bruto de Funalia trogii e o caldo inativado de Funalia trogii adicionado da enzima comercial purificada de Trametes versicolor. Utilizando nos experimentos somente a enzima purificada, menor percentual de remoção foi obtido (30\% em 240 minutos) e menor estabilidade da enzima (totalmente inativada em 90 minutos) ao longo dos experimentos. O autor sugere que uma interação entre o polietilenoglicol e produtos poliméricos presentes no extrato enzimático conferiram proteção à enzima lacase.

A Figura 7 mostra a variação da atividade em lacase com o tempo de experimento, para cada ensaio deste trabalho (1, utilizando o caldo enzimático bruto sem diluição; 2, diluído em água; e 3, diluído em ABTS). Nela observa-se a manutenção da atividade enzimática ao longo do processo de descoloração de ambos os corantes, independentemente do ensaio utilizado (1, 2 ou 3).

t† a Atividade em lacase igual a 48,1 U L-1. ${ }^{\mathrm{b}}$ Atividade em lacase igual a 56,3 U L-1. ${ }^{c}$ Utilizando o caldo enzimático de diluído em ABTS. 

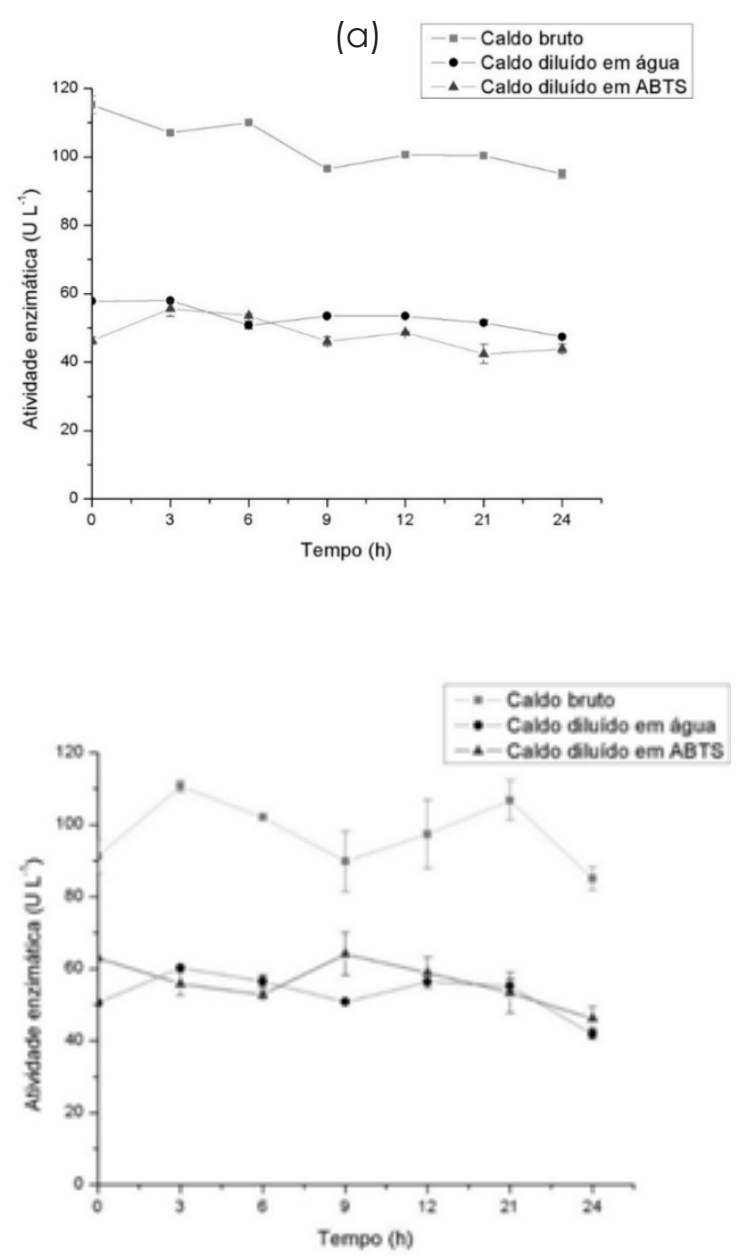

Figura 7 - Atividade em lacase \pm erro padrão, ao longo do tempo, para os experimentos utilizando os corantes (a) Red 50 e (b) Blue 56

A polaridade do meio de cultivo pode influenciar na atuação e na manutenção da atividade da enzima. Solventes com alta polaridade tendem a aumentar a solubilidade dos substratos polares no meio de cultivo, propiciando reações mais rápidas e seletivas.3. Talvez esta pudesse ser uma explicação do porquê, neste trabalho, percentuais de descoloração maiores foram obtidos utilizando-se o caldo enzimático diluído em ABTS, seguido do diluído em água e, por último, o caldo enzimático bruto sem diluição. A atividade enzimática está relacionada à quantidade de água ligada à proteína e não à concentração de água nos solventes orgânicos.37 Assim, maior atividade enzimática pode ser relacionada à atividade de água, independentemente do solvente utilizado. A água aumentaria a mobilidade e a flexibilidade dos sítios ativos da enzima e a polarização da estrutura proteica.

Durante os três experimentos o valor de $\mathrm{pH}$ manteve-se, independentemente do ensaio (1, 2 ou 3), na faixa de 6,0 a 7,0. Em valores de pH muito ácidos ou básicos, a desnaturação e, consequentemente, a inativação da enzima ocorrem. Assim, o controle rigoroso desse parâmetro se faz necessário durante experimentos utilizando-se enzimas.7 Neste trabalho, porém, como o pH manteve-se durante 
todo o experimento próximo da neutraljiflade, gastos adicionais com esse tipo de controle não são necessários.

Em relação à toxicidade, em testes realizados com o microcrustáceo Daphnia magna, observou-se redução da toxicidade após o tratamento da solução de corante com o caldo enzimático de Pleurotus sajor-caju. Para o corante Blue 56 (100 mg L-1) obteve-se redução estatisticamente significativa, no valor da CE50 de $25,9 \%$ para $21,3 \%$, ao final do ensaio 3 (utilizando-se o caldo enzimático bruto diluído em ABTS). Para o corante Red 50 não foi possível determinar o valor de CE50, pois mesmo utilizando-se fator de diluição igual a $0,5 \%$, antes e após tratamento enzimático, não foi possível observar nenhum dos organismos-teste vivos e/ou móveis. Pode-se, então, considerar esse corante mais tóxico que o Blue 56.

Em estudos relacionados à descoloração e detoxificação de corantes, outros autores 12 também observaram diminuição da toxicidade do efluente, concomitantemente à degradação do corante, na maioria dos casos. Ribeiro,38 entretanto, afirma que a descoloração nem sempre é uma indicação de detoxificação bem sucedida. Haja vista os resultados obtidos neste trabalho em relação ao corante Red 50, apesar da parcial descoloração, a solução ainda permaneceu bastante tóxica para o teste agudo com o microcrustáceo Daphnia magna. Quando a detoxificação acontece, os produtos da degradação dos corantes, por lacases fúngicas, por exemplo, não conferem efeito tóxico ao efluente tratado.1

Foram testadas por outros autores 36 a descoloração e remoção da toxicidade por fungos basidiomicetos (Pleurotus ostreatus e duas linhagens de Pleurotus sajor-caju CCB 020 e PSC 94/03) de efluente têxtil coletado após o tratamento biológico na Estação de Tratamento de Efluente (ETE) de Americana, SP, contendo uma mistura de corantes pertencentes às classes das antraquinonas e indigóides. A toxicidade do efluente foi avaliada utilizando como bioindicadores o organismo Hydra attenuata, a alga Selenastrum capricornutum e sementes de alface (Lactuca sativa). Os resultados dos testes com H. attenuata e S. capricornutum mostraram redução da toxicidade após o tratamento fúngico.36 Outros autores39 realizaram ensaio de descoloração e detoxificação de água residuária sintética contendo os corantes Black 5, Orange 16, Blue 79, Red 60 e Blue 56 (250 mg L-1) por Pleurotus sajor-caju. Estes observaram descoloração de $79 \%$ em 24 horas. A toxicidade foi medida com Artemia salina antes e após o tratamento. A água sintética residuária foi caracterizada como tóxica antes do tratamento e, após quatro horas de tratamento, teve sua toxicidade diminuída em 52,4\%.39 Ribeiro38 realizou ensaio de toxicidade utilizando sementes de alface (Lactuca sativa L.) cv. Maravilha de Verão (Topseed), para o corante Remazol Brilliant Blue R, antes e após tratamento com Pleurotus ostreatus e Pleurotus pulmonarius.38 A autora observou diminuição da toxicidade após o tratamento com Pleurotus pulmonarius, sendo observado efeito tóxico quando se utilizou o tratamento com Pleurotus ostreatus. 


\section{CONCLUSÃO}

O caldo enzimático obtido de Pleurotus sajor-caju mostrou-se eficiente na descoloração/degradação dos corantes Red 50 e Blue 56, sendo observada maior taxa de descoloração no ensaio 3, ou seja, quando se utilizou no meio reativo o caldo enzimático bruto diluído em ABTS (1,3 e 1,9×10-2 mg U-1 h-1, para os corantes Red 50 e Blue 56, respectivamente). A utilização do caldo enzimático bruto, sem nenhum processo de extração ou purificação enzimática, traz vantagens para o processo de descoloração, pois gastos adicionais após a sua produção não são necessários. A enzima lacase manteve-se ativa, e o valor de pH constante ao longo de todos os experimentos. Assim, gastos adicionais para a manutenção do pH, em decorrência da sensibilidade da enzima a esse parâmetro, também são desnecessários. A toxicidade após o tratamento enzimático apresentou diminuição estatisticamente significativa para o corante Blue 56. Para o corante Red 50, apesar de este ter apresentado descoloração, não se observou diminuição da sua toxicidade.

\section{Agradecimentos}

Ao Conselho Nacional de Desenvolvimento Científico e Tecnológico (CNPq) e ao Fundo de Apoio à Pesquisa da Univille (FAP/Univille).

\section{REFERÊNCIAS}

1. Chhabra M, Mishra S, Sreekrishnan TR. Combination of chemical and enzymatic treatment for efficient decolorization/degradation of textile effluent: High operational stability of the continuous process. Biochem Eng J. 2015; 93:17-24. doi:10.1016/j.bej.2014.09.007

2. Holkar CR, Jadhav AJ, Pinjari DV, Mahamuni NM, Pandit AB. A critical review on textile wastewater treatments: Possible approaches. J Environ Manage. 2016; 182:351-66. doi:10.1016/j.jenvman.2016.07.090

3. Farias S, Mayer DA, Oliveira D, Souza SMAGU, Souza AAU. Free and Ca-alginate beads immobilized Horseradish peroxidase for the removal of reactive dyes: an experimental and modeling study. Appl Biochem Biotechnol. 2017; 184(4):1290306. doi:10.1007/s12010-017-2399-2 
4. Christie RM. Colour Chemistry. Cambridge: The Royal Society of Chemistry; 2015.

5. Singh RL, Singh PK, Singh RP. Enzymatic decolorization and degradation of azo dyes - A review. Int Biodeterior Biodegradation. 2015; 104:21-31. doi:10.1016/j. ibiod.2015.04.027

6. Silva LAS, Oliveira JM, Duarte EAA, Barreto NSE, Cazetta ML. Descoloração do corante Azul Brilhante de Remazol R por leveduras isoladas de moluscos do Rio Subaé, no estado da Bahia, Brasil. Eng. Sanit Ambient. 2017; 22(6):1065-74. doi: 10.1590/s1413-41522017157568

7. Das A, Bhattacharya S, Panchanan G, Navya BS, Nambiar P. Production, characterization and congo red dye decolourizing efficiency of a laccase from Pleurotus ostreatus MTCC 142 cultivated on co-substrates of paddy straw and corn husk. Genet Eng Biotechnol J. 2016; 14:28188. doi:10.1016/j.jgeb.2016.09.007

8. Sen SK, Raut S, Bandyopadhyay P, Raut S. Fungal decolouration and degradation of azo dyes: A review. Fungal Biol. Rev. 2016; 30:112-33. doi:10.1016/j.fbr.2016.06.003

9. Zhang H, Zhang S, He F, Qin X, Zhang X, Yang Y. Characterization of a manganese peroxidase from white-rot fungus Trametes sp.48424 with strong ability of degrading different types of dyes and polycyclic aromatic hydrocarbons. J Hazard Mater. 2016; 320:265-77. doi:10.1016/j. jhazmat.2016.07.065

10. Ergun SO, Urek RO. Production of ligninolytic enzymes by solid state fermentation using Pleurotus ostreatus. Ann Agrar Sci. 2017; 15(2):273-7. doi:10.1016/j.aasci.2017.04.003

11. Erkurt HA. Biodegradation and detoxification of BPA: Involving laccase and a mediator. Clean - Soil, Air, Water. 2015; 43(6):932-9. doi:10.1002/clen.201400628 
12. Palmieri G, Cennamo G, Sannia G. Remazol Brilliant Blue R decolourisation by the fungus Pleurotus ostreatus and its oxidative enzymatic system. Enzyme Microb Technol. 2005; 36(1):17-24. doi:10.106/j.enzmictec.2004.03.026

13. Ballaminut, N. Caracterização do processo de descoloração de corante reativo diazo por basidiomicetos tropicais [dissertação] [internet]. São Paulo: Universidade de São Paulo; 2016. [acesso em 2017 ago 15]. Disponível em: www.teses.usp.br/teses/disponiveis/87/.../NaraBallaminut_Corrigida_ Doutorado_P.pdf

14. Majeau J-A, Brar SK, Tyagi RD. Laccases for removal of recalcitrant and emerging pollutants. Bioresour. Technol. 2010; 101:2331-50. doi:10.1016/j. biortech.2009.10.087

15. Ottoni CA, Santos C, Kozakiewicz Z, Lima N. White-rot fungi capable of decolourising textile dyes under alcaline conditions. Folia Microbiol. 2013; 58(3):187-93. doi:10.1007/s12223-012-0196-4

16. Pohl, J. M. Avaliação do potencial de descoloração de enzimas produzidas em cultivo submerso por Pleurotus sajor-caju [trabalho de conclusão de curso]. Joinville: Universidade da Região de Joinville, 2013.

17. Kroetz, M. Avaliação da capacidade de descoloração de corantes têxteis por diferentes enzimas produzidas por Pleurotus sajor-caju [trabalho de conclusão de curso] Joinville:Universidade da Região de Joinville, 2012.

18. Associação Brasileira de Normas Técnicas. Norma Brasileira n.o 12713, de 19 de dezembro de 2009, institui metodologia sobre Ecotoxicologia aquática - Toxicidade aguda - Método de ensaio com Daphnia ssp (crustácea, Cladocera). Diário Oficial da União, Rio de Janeiro; 2016.

19. Conselho Nacional do Meio Ambiente. Resolução $n^{\circ}$ 357, de 17 de março de 2005. Diário Oficial da União, Brasília, DF; 2005. 
20. Furlan SA, Virmond LJ, Miers D, Bonatti M, Gern RMM, Jonas R. Mushroom strains able to grow at high temperatures and low $\mathrm{pH}$ values. World J Microbiol Biotechnol. 1997; 13:689-92. doi:10.1023/A:1018579123385

21. Rampinelli JR. Utilização de casca de banana para a produção de lacase por Pleurotus sajor-caju CCB 019 [tese] [internet]. Florianópolis: Universidade Federal de Santa Catarina; 2016 [acesso em 2017 ago 10]. Disponível em: https:// repositorio.ufsc.br/xmlui/handle/123456789/174150

22. Furlan SA, Gern RMM, Wisbeck E, Bonatti M, Silveira MLL, Silva HH. Possibilities of Pleurotus applications in food, health and environmental technologies. In Koutinas A, Pandey A, Larroche C, organizadores. Current topics on Bioprocesses in Food Industry. Nova Delhi: Asiatech; 2008. p. 482-495.

23. Buswell JA, Ca Y, Chang S. Effect of nutrient nitrogen and manganese on manganese peroxidase and laccase production by Lentinula (Lentinus) edodes. FEMS Microbiol Immunol. 1995; 128(1):81-7. doi:10.1111/j.1574-6968.1995. tb07504.x

24. International Organization for Standardization. Water quality - Determination of the inhibition of the mobility of Daphnia magna Straus (Cladocera, Crustacea) - Acute toxicity test. Genebra; 1996.

25. Rorabacher DB. Statistical treatment for rejection of deviant values: critical values of Dixon's "Q" parameter and related subrange ratios at the $95 \%$ confidence level. Anal. Chem. 1991; 63:139-46. doi:10.1021/ac00002a010

26. Brown TL. Química a ciência central. São Paulo: Pearson; 2005.

27. Wikimedia Commons contributors. File: Colorwheel wavelengths.png [Internet] 2016 [acesso em 2017 ago 10]. Disponível em: https://commons.wikimedia. org/w/index.php?title=File:Colorwheel_wavelengths. png\&oldid=218406737 
28. Li X, et al. Mechanisms of $\mathrm{Cd}$ and $\mathrm{Cr}$ removal and tolerance by macrofungus Pleurotus ostreatus HAU-2. J Hazard Mater. 2017; 330:1-8. doi:10.1016/j. jhazmat.2017.01.047

29. Wirasnita R, Hadibarata T. Potential of the white-rot fungus Pleurotus pulmonarius F043 for degradation and transformation of fluoranthene. Pedosphere. 2016; 26(1):49-54. doi:10.1016/S1002-0160(15)60021-2

30. Chang B-V, Chang Y-M. Biodegradation of toxic chemicals by Pleurotus eryngii in submerged fermentation and solid-state fermentation. J Microbiol Immunol Infect. 2016; 49:175-81. doi:10.1016/j.jmii.2014.04.012

31. Teixeira RSS, Pereira PM, Ferreira-Leitão VS. Extraction and application of laccases from shimeji mushrooms (Pleurotus ostreatus) residues in decolourisation of reactive dyes and a comparative study using commercial laccase from Aspergillus oryzae. Enzyme Res. 2010; 1-8. doi:10.4061/2010/905896

32. Rosolen LA, Monteiro RTR, Dellamatrice PM, Kamida HM. Biodegradação de efluente têxtil e nove corantes técnicos utilizando fungos basidiomicetos. Quím. Têxt. 2004; 76:44-52.

33. Batistela DM. Estudo da atividade e estabilidade de lacases em líquidos iônicos [tese] [Internet]. São Paulo: Universidade de São Paulo; 2011 . [acesso em 2017 ago 10]. Disponível em: www.teses.usp.br/teses/...26052011 .../ VersaoCorrigidaDissertDanielaMoraesBatistela.pdf

34. Dâassi D, Prieto A, Zouari-Mechichi H, Martínez MJ, Nasri M, Mechichi T. Degradation of bisphenol A by different fungal laccases and identification of its degradation product. Int. Biodeterioration Biodegrad. 2016; 110:181-8. doi:10.1016/j.ibiod.2016.03.017 
35. Hou H, Zhou J, Wang J, Du C, Yan B. Enhancement of laccase production by Pleurotus ostreatus and its use for the decolorization of anthraquinone dye. Process Biochem. 2004; 39:1415-9. doi:10.1016/S0032-9592(03)00267-X

36. Dellamatrice PM, Monteiro RTR, Kamida HM, Nogueira NL, Rossi ML, Blaise C. Decolourization of municipal effluent and sludge by Pleurotus sajor-caju and Pleurotus ostreatus. World J Microbiol Biotechnol. 2005; 21 (8-9):1363-9. doi:10.1007/s $11274-005-5143-y$

37. Lima AWO, Angnes L. Biocatálise em meios aquo-restritos: fundamentos e aplicações em química analítica. Quím. Nova. 1999; 22(2): doi:10.1590/S010040421999000200015

38. Ribeiro APA. Efeito de fungos basidiomicetos na descoloração e fitotoxicidade de corante sintético e efluente têxtil [tese] [Internet]. Lavras: Universidade Federal de Lavras; 2013. [acesso em 2017 ago 10]. Disponível em: http://repositorio.ufla. br/bitstream/1/961/2/DISSERTA\%C3\%87\%C3\%83O_Efeito\%20de\%20fungos\%20 basidiomicetos\%20na\%20descolora\%C3\%A7\%C3\%A30\%20e\%20fitotoxicidade\%20 de\%20corante\%20sint\%C3\%A9tico\%20e\%20efluente\%20t\%C3\%AAxtil.pdf

39. Singh AD, Vikineswary S, Abdullah N, Sekaran M. Enzymes from spent mushroom substrate of Pleurotus sajor-caju for the decolourisation and detoxification of textile dyes. World J Microbiol Biotechnol. 201 1; 27:535-45. doi:10.1007/s1 1274010-0487-3

Data de submissão: 03 de abril de 2018 Avaliado em: 09 de abril de 2018 (AVALIADOR A) Avaliado em: 10 de abril de 2018 (AVALIADOR B) Aceito em: 29 de abril de 2018 